\title{
Uridine - An Indicator of Post-Exercise Uric Acid Concentration and Blood Pressure
}

\author{
W. DUDZINSKA ${ }^{1}$, A. LUBKOWSKA ${ }^{2,1}$, B. DOLEGOWSKA ${ }^{3}$, M. SUSKA ${ }^{1}$, M. JANIAK ${ }^{1}$ \\ ${ }^{1}$ Department of Physiology, Faculty of Biology, University of Szczecin, Szczecin, Poland, \\ ${ }^{2}$ Laboratory of Physical Medicine, Faculty of Health Sciences, Pomeranian Medical University \\ in Szczecin, Szczecin, Poland, ${ }^{3}$ Department of Laboratory Diagnostics and Molecular Medicine, \\ Pomeranian Medical University in Szczecin, Szczecin, Poland
}

Received March 3, 2014

Accepted August 22, 2014

On-line December 3, 2014

\section{Summary}

Studies have shown that uridine concentration in plasma may be an indicator of uric acid production in patients with gout. It has been also postulated that uridine takes part in blood pressure regulation. Since physical exercise is an effective tool in treatment and prevention of cardio-vascular diseases that are often accompanied by hyperuricemia and hypertension, it seemed advisable to attempt to evaluate the relationship between oxypurine concentrations (Hyp, Xan and UA) and that of Urd and BP after physical exercise in healthy subjects. Sixty healthy men $\left(17.2 \pm 1.71\right.$ years, BMI $23.2 \pm 2.31 \mathrm{~kg} \mathrm{~m}^{-2}, \mathrm{VO}_{2 \max }$ $54.7 \pm 6.48 \mathrm{ml} \mathrm{kg}^{-1} \mathrm{~min}^{-1}$ ) took part in the study. The subjects performed a single maximal physical exercise on a bicycle ergometer. Blood for analyses was sampled three times: immediately before exercise, immediately after exercise, and in the 30th min of rest. Concentrations of uridine and hypoxanthine, xanthine and uric acid were determined in whole blood using high-performance liquid chromatography. We have shown in this study that the maximal exercise-induced increase of uridine concentration correlates with the post-exercise increase of uric acid concentration and systolic blood pressure. The results of our study show a relationship between uridine concentration in blood and uric acid concentration and blood pressure. We have been the first to demonstrate that a maximal exercise-induced increase in uridine concentration is correlated with the post-exercise and recovery-continued increase of uric acid concentration in healthy subjects. Thus, it appears that uridine may be an indicator of post-exercise hyperuricemia and blood pressure.

\section{Key words}

Uridine $\bullet$ Uric acid $\bullet$ Blood pressure $\bullet$ Exercise

\section{Corresponding author}

W. Dudzinska, Department of Physiology, Faculty of Biology, University of Szczecin, Felczaka 3c, 71-412 Szczecin, Poland. Fax: +48-91-444-15-50. E-mail: wiola@univ.szczecin.pl

\section{Introduction}

Uridine (Urd) is a pyrimidine nucleoside. On the one hand, it is a product of pyrimidine nucleotide degradation $(\mathrm{UTP} \rightarrow \mathrm{UDP} \rightarrow \mathrm{UMP} \rightarrow \mathrm{Urd}$ ) but, on the other hand, it is an important precursor in their biosynthesis. Through the uridine salvage pathway, Urd can be converted to UMP and then to other pyrimidine nucleotides $(\mathrm{Urd} \rightarrow \mathrm{UMP} \rightarrow \mathrm{UDP} \rightarrow \mathrm{UTP})$. Hence, the bioavailability of Urd as a substrate in the synthesis of RNA, bio-membranes (via the formation of pyrimidinelipid conjugates) and glutathione (via the formation of pyrimidine-sugar conjugates) is important for proper functioning of cells. Another role of uridine can be seen in the nervous system. Not only does it demonstrate the ability to maintain brain metabolism during severe hypoglycemia and ischemia, but also it acts as a physiological sleep regulator. In the clinical setting it can be used in the treatment of autism with seizures and pyrimidine-deficient genetic diseases like orotic aciduria too. It was also proven that administration of uridine improves cognitive deficits in people and spontaneously hypertensive rats (Löffler et al. 2005, De Bruin et al. 2003, Silei et al. 2000).

Many factors regulating intra- and extracellular Urd concentrations have been identified. The mechanism 
of its action has also been established both under physiological and pathological conditions (Connolly and Duley 1999, Löffler et al. 2005, Yamamoto et al. 2011). Evidence for the fact that changes in the Urd concentration in blood may influence the biological effect of its action has been provided, too (Yamamoto et al. 2011).

In our previous study, we have demonstrated that high-intensity physical exercise leads to an increase in the Urd concentration in blood (Dudzinska et al. 2010). Its post-exercise increase correlated with an increase in the concentration of hypoxanthine (Hyp) allowed statement that physical exercise stimulates not only the catabolism of purine nucleotides but also that of pyrimidines. Similarly, Yamamoto et al. (1997a) have shown a significant increase in the Urd concentration after physical exercise of much lower intensity. Therefore, physical exercise is a factor leading to a postexercise and recovery-continued increase in the Urd and Hyp concentrations (Yamamoto et al. 1997a, Dudzinska et al. 2010). The elevations in plasma Hyp after intense exercise have a direct implication on plasma uric acid (UA) levels as the liver oxidizes Hyp to UA and releases it into the blood at a rate proportional to the increase in plasma Hyp (Hellsten-Westing et al. 1989). Although UA is the end product of purine nucleotide metabolism, an exercise-induced increase in the concentration of Urd (a product of pyrimidine nucleotide catabolism) may be related to a post-exercise increase in the concentration of UA (end product of purine nucleotide catabolism). There are on information in the available literature on the evaluation of post-exercise changes in the Urd concentration in relation to post-exercise hyperuricemia in healthy subjects. The only information indicating a relationship of Urd to UA is from the study by Yamamoto et al. (1997b) who have shown an increase in the concentration of that nucleoside in blood in patients with gout of the overexcretion (overproduction) type versus the underexcretion type. Moreover, they have shown a significant correlation between plasma Urd concentration and 24-h urinary excretion of UA. In the opinion of Yamamoto's team (1997b), plasma Urd concentration may be a marker of UA production and can be used to separate hyperuricemia into the overexcretion (overproduction) and underexcretion types. Furthermore, it has been demonstrated that high plasma uric acid levels are positively associated with increased incidences of hypertension in adults (Chu et al. 2000). More specifically, plasma uric acid levels significantly predict diastolic hypertension, but not systolic hypertension (Leite 2011). A relationship between elevated UA concentration in plasma and the occurrence of hypertension has been very well documented in many clinical and epidemiological studies (Messerli et al. 1980, Nagahama et al. 2004, Alper et al. 2005, Sundstrom et al. 2005). It has been shown that uric acid production in mild hypertension is not intensified, whereas its renal excretion is significantly decreased (Tykarski et al. 2004). By contrast, in severe hypertension which leads to progressive ischemia of tissues and, in consequence, to hypoxia, increased ATP degradation and intensified formation of the end products of purine degradation (Hyp, Xan and UA) are not excluded from the causes for an increase in the UA concentration (Fiaschi et al. 1997, Ohtahara et al. 2001, Tykarski et al. 2004). Ohtahara et al. (2001), using the semi-ischemic forearm test to examine the release of Hyp from skeletal muscles in essential hypertensive patients have shown an increase in its release when compared to normotensive subjects, which points to the fact that skeletal muscles may be an important source of UA in hypertension. By contrast, Fiaschi et al. (1977) have observed that intravenous fructose infusion causes an increase in the UA concentration in the plasma of patients with hypertension to a greater degree than in normotensive subjects. It is also known that fructose, the metabolism of which leads to quick ATP depletion (fructose phosphorylation is closely associated with ATP degradation), also results in an increase in the Urd concentration in blood (Yamamoto et al. 1997c). By contrast, Tykarski et al. (2004) have shown an increase both in the UA concentration and the AMP-deaminase activity in red blood cells in severe hypertension when compared to the mild one, which gives the basis to assume that purine nucleotide degradation and oxypurine conversion to uric acid is more intensified in severe hypertension when compared to the mild one. Therefore, a cause for hyperuricemia in hypertension, apart from impaired excretion, may be increased UA production. It has also been demonstrated that myogenic purine degradation caused by exerciseinduced hypoxia ( $\mathrm{ATP} \rightarrow \mathrm{ADP} \rightarrow \mathrm{AMP} \rightarrow$ hypoxanthine) is augmented in subjects with hypertension (Otahara et al. 2001, Hamada et al. 2007). On the other hand, Macdonald et al. (1984) have provided evidence for the fact that Urd, UMP and UDP increased blood pressure (BP) when infused into intact anaesthetized rats and had similar effects on the perfusion pressure in the rat isolated perfused kidney. It has also been proven that $\mathrm{Up}_{4} \mathrm{~A}-$ 
induced contraction is enhanced in renal arteries from DOCA-salt rats. Enhanced P2Y receptor signaling and activation of the extracellular signal-regulated kinases (ERK) pathway together represent a likely mechanism mediating the enhanced $\mathrm{Up}_{4} \mathrm{~A}$-induced contraction. $\mathrm{Up}_{4} \mathrm{~A}$ might be of relevance in the pathophysiology of vascular tone regulation and renal dysfunction in arterial hypertension (Matsumoto et al. 2011).

As mentioned above, studies succeeded to establish an association between the Urd concentration and hyperuricemia and BP in the group of patients with gout and hypertension. Therefore, in our opinion, there is a rationale behind it to evaluate the relationship between the concentration of oxypurines (Hyp, Xan and UA) and that of Urd and BP after physical exercise, all the more that physical exercise is regarded to be an effective, nonpharmacological tool in the treatment of diseases connected with hyperuricemia and hypertension (Blair et al. 2001). According to our knowledge, there are no information in the available literature on that subject.

\section{Methods}

\section{Subjects}

The study population consisted of 60 healthy men, volunteers, aged 17.2 \pm 1.71 years, with normal body weight and blood pressure (systolic blood pressure [SBP] $<140 \mathrm{~mm} \mathrm{Hg}$, diastolic blood pressure [DBP] $<90 \mathrm{~mm} \mathrm{Hg}$ ). Participants' anthropometrical and clinical characteristics are shown in Table 1. They had no history of any metabolic and cardiovascular diseases. Participants were nonsmokers and refrained from taking any medications or supplements known to affect metabolism.

The subjects were fully informed of any risks and discomfort associated with the experimental procedures before giving their consent to participate. The study was approved by the local ethics committee in accordance with the Helsinki Declaration.

Exercise test was performed at the laboratory of the Department of Physiology, Faculty of Biology, University of Szczecin in the early-morning hours. The subjects reported to the laboratory a few hours after having a light breakfast (without tea and coffee).

\section{Anthropometric and clinical measurements}

Body height $(\mathrm{cm})$ was measured to the nearest centimetre using a rigid stadiometer.

Body mass $(\mathrm{kg})$ was measured in underwear to the nearest $0.1 \mathrm{~kg}$ using an electronic scale.
Body mass index (BMI) was calculated by dividing weight in kilograms by height in square meters $\left(\mathrm{kg} / \mathrm{m}^{2}\right)$.

Blood pressure (BP) while resting and after maximal exercise were measured 3 times in the seated position using a calibrated sphygmomanometer. The average of the 3 readings was used for the representative examination value. The measurement was performed under controlled conditions in a quiet room. The cuff of the blood pressure monitor was placed around the upper right arm.

The mean arterial pressure (MAP) was calculated as: $\mathrm{MAP}=\mathrm{DBP}+1 / 3 \times$ pulse pressure, where pulse pressure $=\mathrm{SBP}-\mathrm{DBP}$.

Table 1. Characteristics of the subjects.

\begin{tabular}{ll}
\hline Parameters & Mean \pm SD \\
\hline Age (years) & $17.2 \pm 1.71$ \\
Body height $(\mathrm{cm})$ & $184.2 \pm 5.89$ \\
Body mass $(\mathrm{kg})$ & $78.6 \pm 10.06$ \\
BMI $\left(\mathrm{kg} \mathrm{m}^{-2}\right)$ & $23.2 \pm 2.31$ \\
HR rest $(\mathrm{bpm})$ & $68.4 \pm 7.34$ \\
$\mathrm{SBP}(\mathrm{mm} \mathrm{Hg})$ & $125.9 \pm 7.75$ \\
$D B P(\mathrm{~mm} \mathrm{Hg})$ & $68.1 \pm 7.64$ \\
$M A P(\mathrm{~mm} \mathrm{Hg})$ & $87.2 \pm 5.64$ \\
$\operatorname{VO} O_{2 \max }\left(\mathrm{ml} \mathrm{kg}^{-1} \mathrm{~min}^{-1}\right)$ & $54.7 \pm 6.48$ \\
\hline
\end{tabular}

$\mathrm{n}=60$; BMI - body mass index; HR - heart rate; SBP - systolic blood pressure; DBP - diastolic blood pressure; MAP - mean arterial pressure; $\mathrm{VO}_{2 \max }$ - maximum of oxygen uptake

\section{Exercise protocol}

The participants were subjected to a progressive ergocycle test with incremental intensity until exhaustion, establishing their maximal oxygen uptake $\left(\mathrm{VO}_{2 \max }\right)$ to assess aerobic capacities. The exercise was preceded by a 5 min warm-up $(25 \mathrm{~W})$. The test was performed on a bicycle ergometer (Kettler X-7, Germany), beginning with a work load of $1 \mathrm{~W}$ per $\mathrm{kg}$ of fat free mass $\left(1 \mathrm{~W} \mathrm{~kg}_{\mathrm{FFM}}^{-1}\right)$ that was increased by half of this value $\left(0.5 \mathrm{~W} \mathrm{~kg}_{\mathrm{FFM}}^{-1}\right)$ every $3 \mathrm{~min}$ until volitional exhaustion. The criterion of the $\mathrm{VO}_{2 \max }$ was the achievement of the expected maximal heart rate $\left(\mathrm{HR}_{\max }\right)$ and a lack of increase in oxygen uptake $\left(\mathrm{VO}_{2}\right)$ despite the increasing work load.

During the exercise, the following variables were measured continuously: oxygen uptake $\left(\mathrm{VO}_{2}\right)$, 
expired carbon dioxide $\left(\mathrm{VCO}_{2}\right)$, minute ventilation (VE), tidal volume (TV), respiration frequency (RF), ventilator equivalent ratio for oxygen $\left(\mathrm{VEVO}_{2}^{-1}\right)$, ventilatory equivalent ratio for carbon dioxide $\left(\mathrm{VEVCO}_{2}^{-1}\right)$ and heart rate (HR). During the exercise, oxygen uptake $\left(\mathrm{VO}_{2}\right)$ was measured continuously using an Oxycon gas analyzer (Jaeger, Germany). Using a Polar S610 heart rate monitor (Polar, Finland), we registered resting heart rate and its change during effort, up to HRmax.

\section{Blood analysis}

Blood samples were obtained from the antecubital forearm vein immediately before exercise, immediately after exercise, and $30 \mathrm{~min}$ after exercise testing.

Concentrations of uridine and oxypurines were determined in whole blood using high-performance liquid chromatography. The samples $(500 \mu \mathrm{l})$ of heparinized blood were deproteinized with an equal volume of $1.3 \mathrm{M}$ $\mathrm{HClO}_{4}$, mixed, and then centrifuged at $20,000 \mathrm{G}$ for $5 \mathrm{~min}$ at $4{ }^{\circ} \mathrm{C}$. The supernatant $(400 \mu \mathrm{l})$ was neutralized with 130-160 $\mu \mathrm{l}$ of $1 \mathrm{M} \mathrm{K}_{3} \mathrm{PO}_{4}$ (to $\mathrm{pH}$ 5-7). The neutralized extract was again centrifuged as above, and the supernatant was stored at $-80^{\circ} \mathrm{C}$ until analysis.

Chromatographic analysis was performed using a Hewlett-Packard series 1100 chromatograph according to the method used by Smolenski et al. (1990).

Aliquots of $100 \mu$ of the obtained samples were injected into the sample loop and uridine, hypoxanthine, xanthine and uric acid were separated using a gradient elution system (buffer A - $150 \mathrm{mM} \mathrm{K \textrm {K } _ { 2 }} \mathrm{PO}_{4} / \mathrm{K}_{2} \mathrm{HPO}_{4}$, $150 \mathrm{mM} \mathrm{KCl} \mathrm{pH} \mathrm{6.0;} \mathrm{buffer} \mathrm{B}-15 \%$ solution of acetonitrile in buffer A) at a flow rate of $1 \mathrm{ml} / \mathrm{min}$. Peaks were detected by absorbance at $254 \mathrm{~nm}$. The analytical column was maintained at a constant temperature of $25.5^{\circ} \mathrm{C}$.

Concentrations of hypoxanthine, xanthine, uric acid and uridine are given to the whole blood because these compounds are in equilibrium between erythrocytes and plasma thanks to nucleoside transporters.

\section{Statistical analysis}

All values are reported as mean $\pm \mathrm{SD}$. ANOVA with repeated measurements was used to compare data over time. When the ANOVA was significant, (RIR) Tukey's post hoc tests were used to localize the difference. Evaluation of the correlations between the examined variables was made using Pearson's linear correlation coefficient and simple and multiple regression analysis.

In order to determine the independent participation of oxypurines (Hyp, Xan, UA) in the variance of Urd concentration in blood, a multiple regression analysis was performed.

Simple regression analysis included anthropometric parameters, systolic blood pressure value, diastolic blood pressure value, mean blood pressure value, concentration of oxypurines (Hyp, Xa, UA) and that of Urd. The independent variables which correlated with the Urd concentration in simple regression analysis were taken into account in the model of multiple regression analysis. The value $\mathrm{p}<0.05$ was considered statistically significant.

\section{Results}

The characteristics of some of anthropometrical and physiological parameters were presented in Table 1. There were 60 healthy young males enrolled into the study, aged 17.2 \pm 1.71 years, with normal body weigh being evaluated based on BMI (World Health Organization 1998). In the group of male subjects being examined, the time of exercise test was $23.0 \pm 3.47 \mathrm{~min}$, while oxygen consumption at maximum load was $54.7 \pm 6.48 \mathrm{ml} / \mathrm{min} / \mathrm{kg}$, which indicates that the subjects were characterized by a good aerobic endurance for this age group (Astrand and Rodahl 1986) when compared to reference data (Table 1).

According to the European Society of Hypertension (Guidelines Committee 2003) all subjects were normotensive. The mean resting systolic pressure was $125.9 \pm 7.75 \mathrm{~mm} \mathrm{Hg}$, diastolic pressure $68.1 \pm 7.64$ $\mathrm{mm} \mathrm{Hg}$ and heart rate $68.4 \pm 7.34 / \mathrm{min}$ (Table 2). Physical effort performed on a cycle ergometer caused a significant increase in SBP (by $57 \mathrm{~mm} \mathrm{Hg}$ on average) and a considerable decrease in DBP (by about $13 \mathrm{~mm} \mathrm{Hg}$ on average) with no change in MAP. In the 30th min of rest, a return of SBP and DBP values to the rest ones was observed (Table 2).

Physical exercise contributed to almost eightfold increase in the Hyp concentration in blood in relation to the rest values. A significant increase $(\mathrm{P}<0.00001)$ in the Hyp concentration was still observed in the 30th min of rest, which is an indication of the fact that maximal physical exercise induces not only the post-exercise increase of the Hyp concentration but also the continued one (Table 3). 
Table 2. Effect of physical exercise on SBP, DBP and MAP.

\begin{tabular}{llll}
\hline & Pre-exercise & Post-exercise & Rest 30 min \\
\hline$S B P(\mathrm{~mm} \mathrm{Hg})$ & $125 \pm 7.75$ & $178 \pm 18.21^{* \text { (vs. Pre and Rest) }}$ & $125 \pm 7.13$ \\
$D B P(\mathrm{~mm} \mathrm{Hg})$ & $68.1 \pm 7.64$ & $55.6 \pm 9.47^{\text {\#(vs. Pre and Rest) }}$ & $67.6 \pm 6.21$ \\
$M A P(\mathrm{~mm} \mathrm{Hg})$ & $87.2 \pm 5.64$ & $89.9 \pm 10.98$ & $86.7 \pm 4.62$ \\
\hline
\end{tabular}

Values are given as means $\pm \mathrm{SD} ; \mathrm{n}=60 ; * \mathrm{P}<0.00001 ;{ }^{*} \mathrm{P}<0.05 ; \mathrm{SBP}$ - systolic blood pressure; DBP - diastolic blood pressure; MAP mean arterial pressure.

Table 3. Effect of physical exercise on the concentration of oxypurines (hypoxanthine, xanthine, uric acid) and uridine in blood.

\begin{tabular}{llll}
\hline $\boldsymbol{\mu m o l} / \mathbf{l}$ whole blood & Pre-exercise & Post-exercise & Rest 30 min \\
\hline Hyp & $1.8 \pm 1.30$ & $16.6 \pm 7.96^{* \text { (vs. Pre) }}$ & $19.3 \pm 9.40^{*}$ (vs. Pre) \\
Xan & $0.2 \pm 0.09$ & $0.5 \pm 0.45^{*}$ (vs. Pre and Rest) & $0.7 \pm 0.29 *$ (vs. Pre and Post) \\
$U A$ & $211 \pm 37.8$ & $238 \pm 42.2$ & $267 \pm 48.5 *$ (vs. Pre) \\
$U A / H y p+X a$ & $131 \pm 33.79$ & $16.4 \pm 17.02 * *$ (vs. Pre) & $15.3 \pm 7.47 *$ (vs. Pre) \\
Urd & $3.3 \pm 1.08$ & $4.2 \pm 1.21 *$ (vs. Pre) & $4.3 \pm 1.13^{*}$ (vs. Pre) \\
\hline
\end{tabular}

Values are given as means $\pm \mathrm{SD} ; \mathrm{n}=60$; Hyp - hypoxanthine; Xan - xanthine; UA - uric acid; Urd - uridine; $* \mathrm{P}<0.00001$; $* * P<0.000001$

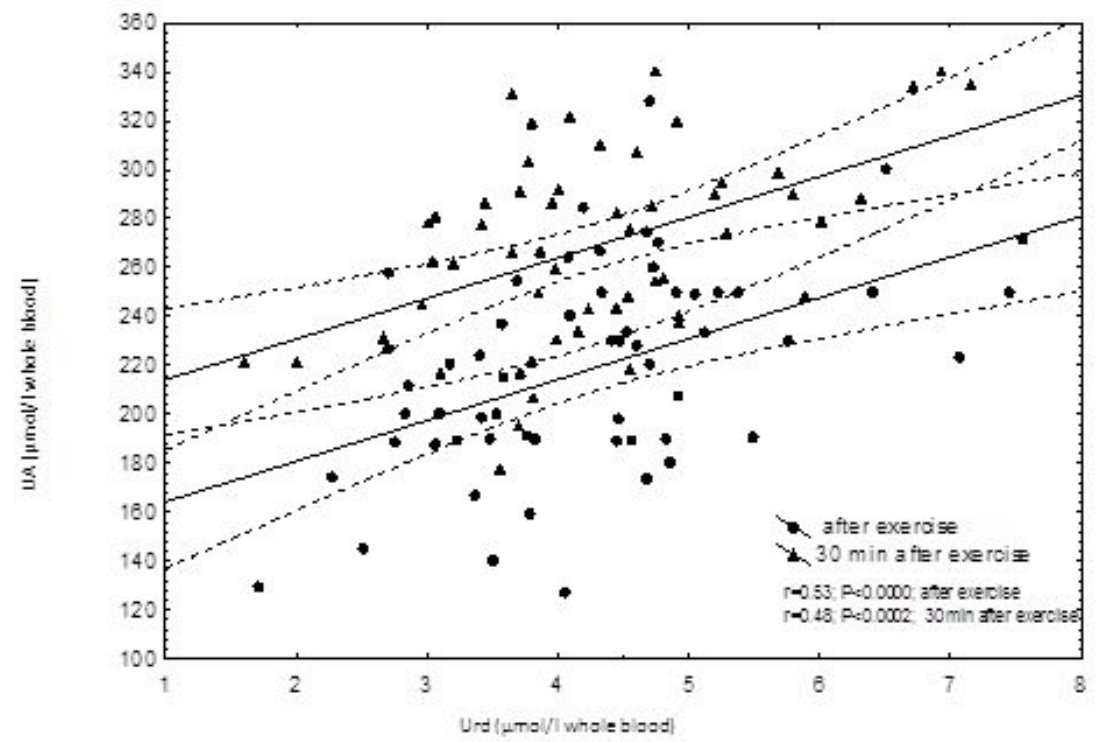

Fig. 1. Correlation between uridine (Urd) concentration and post-exercise and recovery uric acid (UA) concentrations.

The Xan concentration in blood immediately after exercise test reached a value of $0.5 \pm 0.45 \mu \mathrm{mol} / \mathrm{l}$ and differed significantly ( $\mathrm{P}<0.00001)$ from the value being measured before exercise test $(0.2 \pm 0.09 \mu \mathrm{mol} / \mathrm{l})$. An increase in the Xan concentration still continued in the 30 th $\min$ of rest also in relation to the rest value $(\mathrm{P}<0.00001)$ (Table 3).

The presented data show that the UA concentration measured $30 \mathrm{~min}$ after the physical exercise being applied reached a value of $267 \pm 48.5 \mu \mathrm{mol} / 1$ and was significantly higher $(\mathrm{P}<0.0001)$ both in relation to the rest values $(211 \pm 37.8 \mu \mathrm{mol} / \mathrm{l})$ and those being observed immediately after physical exercise $(238 \pm 42.2$ $\mu \mathrm{mol} / \mathrm{l} ; \mathrm{P}<0.0001)$. No significant differences in the UA concentration were observed immediately after physical exercise when compared to the rest values.

The ratio of UA concentration to that of Hyp and Xan was significantly lower immediately after physical exercise, as well as in the 30th min of rest $(\mathrm{P}<0.000001)$ (Table 3). 
The plasma concentration of Urd in humans ranges from 2 to $8 \mu \mathrm{M}$ (Connolly and Duley 1999, Yamamoto et al. 2011). Consequently, the rest value of Urd concentration in the group of male subjects being examined was within the range of values given by other authors. Maximal physical exercise led to a significant increase $(\mathrm{P}<0.00001)$ in the Urd concentration in relation to the values being observed before exercise test. A significant increase $(\mathrm{P}<0.00001)$ in the Urd concentration was still observed in the 30th min of rest, which is an indication of the fact that maximal physical exercise induces not only the post-exercise increase of the Urd concentration but also the continued one (Table 3 ).

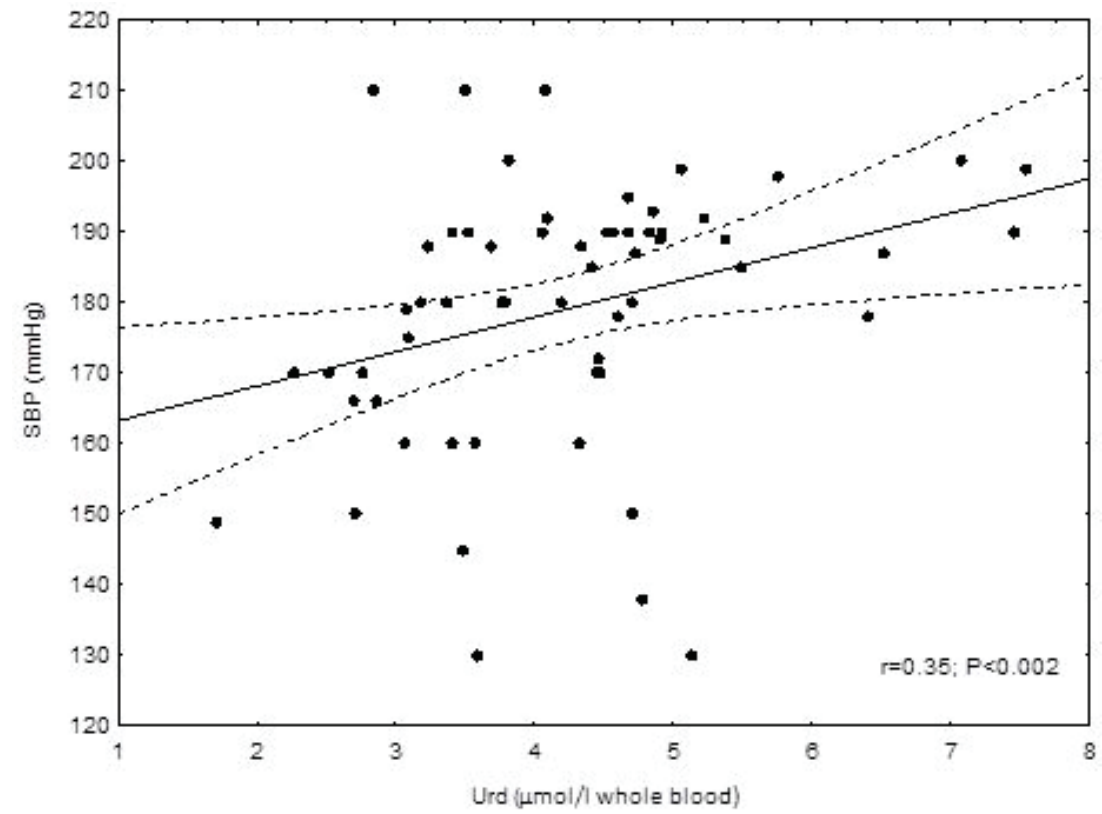

Fig. 2. Correlation between postexercise uridine (Urd) concentration and systolic blood pressure (SBP).

Table 4. Multiple regression analysis for blood uridine after exercise.

\begin{tabular}{llllll}
\hline Predictor & Coefficient & SE & $\boldsymbol{\beta}$ & T value & P value \\
\hline Hyp & 0.015 & 0.015 & 0.120 & 0.985 & NS \\
Xan & 0.009 & 0.003 & 0.328 & 3.206 & $<0.002$ \\
$U A$ & 1.188 & 0.271 & 0.457 & 4.379 & $<0.00005$ \\
SBP & 0.017 & 0.006 & 0.300 & 2.682 & $<0.009$ \\
\hline
\end{tabular}

NS - not significant; Hyp - hypoxanthine; Xan - xanthine; UA - uric acid; $\beta$ - standard coefficient

Table 5. Multiple regression analysis for blood uridine after 30-min recovery.

\begin{tabular}{llllll}
\hline Predictor & Coefficient & SE & $\boldsymbol{\beta}$ & T value & P value \\
\hline Hyp & -0.008 & 0.006 & -0.005 & -0.544 & NS \\
Xan & 0.008 & 0.003 & 0.284 & 2.411 & $<0.0005$ \\
$U A$ & 1.681 & 0.457 & 0.433 & 3.670 & $<0.01$ \\
\hline
\end{tabular}

NS - not significant; Hyp - hypoxanthine; Xan - xanthine; UA - uric acid; $\beta$ - standard coefficient

In the simple regression analysis, the postexercise increase of Urd concentration correlated with a post-exercise increase in the concentration of Hyp $(r=0.30$, $\left.\mathrm{p}<0.0001, \mathrm{R}^{2}=0.10\right), \mathrm{Xan}\left(\mathrm{r}=0.37, \mathrm{p}<0.003, \mathrm{R}^{2}=0.14\right)$ and UA ( $\mathrm{r}=0.53, \mathrm{p}<0.00001, \mathrm{R}^{2}=0.27$ ), respectively (Fig. 1), and $\operatorname{SBP}\left(r=0.35, \mathrm{p}<0.002, \mathrm{R}^{2}=0.13\right.$; Fig. 2). 
In the multiple regression analysis, the postexercise Urd concentration was independently related to the Xan and UA concentrations and SBP (Table 4). In this regard, these variables explained more than $50 \%$ of the post-exercise variance of Urd concentration $\left(\mathrm{R}^{2}=0.53\right)$. The most powerful predictor of post-exercise Urd concentration was UA (Table 4; Fig. 1).

As regards the concentration values being measured in the 30th minute of rest, the multiple regression analysis showed a correlation between the Urd concentration and that of Hyp ( $\mathrm{r}=0.33, \mathrm{p}<0.0002$, $\left.\mathrm{R}^{2}=0.11\right)$, Xan $\left(\mathrm{r}=0.35, \mathrm{p}<0.009, \mathrm{R}^{2}=0.13\right)$ and $\mathrm{UA}$ $\left(r=0.48, p<0.0002, R^{2}=0.23\right.$; Fig. 1) but not with SBP. Assuming the Urd concentration in the 30th min of rest to be a dependent variable and the concentration of Hyp, $X$ an and UA to be independent variables, a multiple regression analysis was applied. It was shown that the Urd concentration was correlated with that of Xan and UA but not with the Hyp concentration (Table 5). Xan and UA explained more than $40 \%$ of the post-exercise variance of Urd concentration $\left(\mathrm{R}^{2}=0.37\right)$. UA proved again to be the most powerful predictor of post-exercise Urd concentration (Table 5, Fig. 1).

\section{Discussion}

We have shown in this study that an increase in the Urd concentration in blood being induced by maximal physical exercise correlates with a post-exercise increase in the Xan and UA concentrations and SBP. To the best of our knowledge, this is the first study to evaluate postexercise relationships between the Urd and UA concentrations and BP in healthy subjects.

It is known that physical exercise, particularly that of high intensity, leads to a decrease in the ATP level in the exercising muscles, with the IMP accumulation accompanying this process (Stathis et al. 1994, Hellsten et al. 1999). Although most IMP is quickly resynthesized to ATP in the purine nucleotide cycle, part of IMP is being however converted to inosine and hypoxanthine after de-phosphorylation (Stathis et al. 1994). After leaving the muscles, they get into blood. Therefore, a post-exercise value of the increase of Hyp concentration, being mainly dependent on exercise intensity (Hellsten-Westing et al. 1991, Sahlin et al. 1991), is an indicator of purine degradation intensity and post-exercise tissue hypoxia. A direct effect of the increase of Hyp concentration is the proportional rate of increase in the concentration of UA in blood which is being formed as a product of the oxidation of oxypurines (Hyp and Xan) in the reaction catalyzed by xanthine oxidoreductase (EC 1.1.1.204). A significant increase in the UA concentration in the 30th min of rest being shown in our study confirms the findings of other authors who have observed an increase in the concentration of that metabolite in the 20th-30th min after intense physical exercise (Hellsten-Westing et al. 1989, 1991, Yamanaka et al. 1992). Thus, the post-exercise changes in the concentration of purine nucleotide degradation products (Hyp, Xan, UA) in blood being observed in our study harmonizes with the studies on post-exercise metabolism of purines and is not the matter under consideration in this study.

We have already demonstrated in our previous study that physical exercise with increasing intensity leads to an increase in the Hyp and Urd concentrations in blood. We found positive correlations between blood Urd levels (indicators of myogenic pyrimidine degradation) and Hyp (indicators of myogenic purine degradation), suggesting that the blood Urd level is related to purine metabolism in skeletal muscles (Dudzinska et al. 2010). Because the increase of Hyp concentration in blood after intense exercise has a direct implication on plasma UA levels as the liver oxidizes Hyp to UA and releases it into the bloodstream at a rate proportional to the increase in plasma Hyp (Sjödin and Hellsten Westing 1990, Hellsten et al. 1999), therefore we have decided in this study to evaluate a relationship between the post-exercise increase of Urd concentration and post-exercise changes in the Xan and UA concentrations. Although the post-exercise increase of Urd concentration in our study was correlated with a post-exercise increase in the Hyp, Xan and UA concentrations, the Urd concentration (dependent variable) in the multiple regression analysis was associated only with the Xan and UA concentrations, both immediately after physical exercise and in the 30th min of rest. Therefore, the results of this study confirm our earlier information on the reason for a post-exercise increase, and lasting in the 30th $\mathrm{min}$, in the Urd concentration which is an exercise-stimulated decrease in the ATP concentration in the exercising muscles (Dudzinska et al. 2010). Moreover, they provide new evidence for the fact that the most powerful predictor for the increase of Urd concentration is an increase in the UA concentration. The higher post-exercise Xan and UA concentrations in blood, the higher Urd concentration in blood. The relationship being demonstrated becomes particularly important in relation to the findings presented 
by Yamamoto et al. (1997b) who have shown an increase in the Urd concentration in patients with gout of the overexcretion type versus the underexcretion type. Moreover, evidence has been provided in that study for the fact that the Urd concentration may be an indicator for increased UA production in patients with hyperuricemia. This is because a positive relationship has been demonstrated between the Urd concentration in plasma and 24-hour urinary UA excretion. On the other hand, no relationship has been shown between plasma Urd concentration and that of UA, which suggests that the Urd concentration does not reflect the changes in the UA concentration in blood. Therefore, the results being obtained in our study are in conflict with those presented by Yamamoto et al. (1997b). Differences in the results become more understandable after analysis of the changes in the concentration of metabolites being examined. Although Yamamoto et al. (1997b) have shown an increase in the UA concentration in plasma both in the group of patients with gout of the overexcretion (overproduction) type and that with gout of the underexcretion type, the Xan and Hyp concentrations did not differ between these groups. It is not known, either, whether an increase in the Xan and Hyp concentrations in blood occurred because these results were not confronted with the control group. Thus, it seems that, on the one hand, the UA concentration in plasma in patients with gout does not reflect its production or excretion (the value of hyperuricemia was the same in both groups) but, on the other hand, the Xan and Hyp concentrations do not illustrate the value of purine degradation in gout (concentrations of oxypurines were the same in the two examined groups). From a theoretical point of view, increased UA production leads to an increase in the concentration of its direct precursors. An increase in the Xan and Hyp concentrations would be all the more higher than that in the UA concentration. It has been found that the ratio of UA concentration to that of Hyp and Xan decreases during increased UA production (Sutton et al. 1980, Sjödin and Hellsten Westing 1990). In our study, the ration of UA concentration to that of Xan and Hyp is significantly decreased, which means that the production of Xan and Hyp, and the same that of UA, is intensified. Thus, it seems that a post-exercise increase in the UA concentration, which corresponds with a post-exercise increase in the Hyp and Xan concentrations, and the relationship between the post-exercise increase of Urd concentration and the Xan and UA concentrations being showed support the fact that Urd is an indicator of the Xan and UA production under conditions of excessive purine catabolism being stimulated by physical exercise.

Under hyperuricemia conditions overproduction of UA is mostly due to increased biosynthesis of purines de novo (Jin et al. 2012). It is known, however, that the UA overproduction is also associated with excessive ATP consumption being caused either by physical exercise (Sutton et al. 1980, Harkness 1988, Sjödin and Hellsten Westing 1990), or by compounds that intensify the ATP degradation (Jin et al. 2012). It is also known that excessive ATP consumption is accompanied by an increase in the Urd concentration (Dudzinska et al. 2010, Yamamoto et al. 1997c, Burakowski et al. 2007). Thus, the results of our present study confirm the coexistence of purine and pyrimidine catabolism and provide evidence for the fact that the product of pyrimidine degradation (Urd) is an indicator of the changes in the Xan and UA concentrations under conditions of bioenergy hypoxia being stimulated by physical exercise. Thus, it seems that Urd may be an indicator of hyperuricemia developing both under conditions of the increase of purine synthesis de novo (Yamamoto et al. 1997b) and under conditions of the increase of ATP consumption, as shown in our present study.

Consequently, the relationship between a postexercise increase in the Urd concentration and that of UA and the Urd concentration and SBP being demonstrated may indicate a potential participation of the Urd molecule in the development of post-exercise hyperuricemia and the increase of BP. Similar relationships have been found by Hamada et al. (2007) in patients with hypertension. The Urd concentration in that group of patients was significantly higher and correlated with SBP ( $r=0.43$; $\mathrm{P}<0.01$ ). Moreover, a significant relationship was also demonstrated between the Urd concentration and that of Hyp being released from the semi-ischemic exercising muscles of the hypertensive patients.

Therefore, the relationship between the Urd concentration and SBP being obtained in our study indicates an association between the increase of Urd concentration and that of SBP. Literature data referring to the participation of Urd in blood pressure regulation show that Urd, UMP and UDP increased blood pressure when infused into intact anesthetized rats and had similar effects on the perfusion pressure in the rat isolated perfused kidney (Macdonald et al. 1984). Moreover, Urd stimulates P2Y receptors, which has a positive inotropic effects on both the heart and blood vessels via formation 
of UMP, UDP and UTP (Hamada et al. 2007). Also Jankowski et al. (2005) investigated the effects of uridine adenosine tetraphosphate $\left(\mathrm{Up}_{4} \mathrm{~A}\right)$ on mean arterial pressure of rats. Both noradrenaline and $\mathrm{Up}_{4} \mathrm{~A}$ increased mean arterial pressure when injected intra-aortically in the anesthetized rat. Although noradrenaline evoked a sharp, short-lasting increase in arterial blood pressure, the same amount of $\mathrm{Up}_{4} \mathrm{~A}$ showed a more prolonged effect on arterial blood pressure (Jankowski et al. 2005).

Blood pressure during exercise is dependent on cardiac output and peripheral resistance. Systolic blood pressure increases with increasing dynamic work as a result of increasing cardiac output, whereas diastolic pressure usually remains about the same or moderately lower. The changes in blood pressure being observed in our study confirm therefore the reports of other authors (O'Brien et al. 2003, Laukkanen and Kurl 2012). Additionally, we have shown that a post-exercise increase in SBP is correlated with the post-exercise increase of Urd concentration, which indicates a potential participation of the Urd molecule in the post-exercise increase of SBP.

We are aware of the fact that reasoning on the metabolism of purines and pyrimidines based on measuring the concentrations of the examined variables and searching for the relationships between them is not free of approximations at least due to the complex mechanism of their elimination: renal excretion, reutilization to the nucleotide pool, and oxidation to UA. Nevertheless, the results of our study indicate an association between uridine concentration and postexercise hyperuricemia and blood pressure. Consequently, it is possible that a continued increase in plasma uridine concentration may play a role in the pathogenesis of hyperuricemia and vascular diseases.

An integral part of the therapy of diseases related to the increase of UA concentration and hypertension is non-pharmacological treatment, including physical exercise. Studies have confirmed the effect of regular physical activity and exercises of moderate intensity on the reduction of risk factors for development of atherosclerosis disease (hypertension, insulin resistance, unfavorable lipid profile, obesity and development of type 2 diabetes). Implementation of more intense exercises $\left(>75 \% \mathrm{VO}_{2 \max }\right)$ may however lead to a transient impairment of purine metabolism, rapid heart rate, and increased blood pressure. The increase of Urd concentration after application of maximal physical exercise confirm our present and previous observations (Dudzinska et al. 2010). Also Yamamoto et al. (1997a) have shown that physical exercise of lower intensity $\left(65 \% \mathrm{VO}_{2 \max }\right)$ is connected with a significant increase in the post-exercise Urd concentration. What is interesting, we have shown that a post-exercise increase in the Urd concentration still continue in the 30th min of rest, i.e. after normalization of blood pressure but not that of UA concentration. Therefore, physical exercise stimulates a continued increase in uridine concentration and the same creates perhaps favorable conditions for hyperuricemia induction through the mechanisms being discussed above.

Summing up, the results of our study show an association between the Urd concentration in blood and that of UA and SBP. We have been the first to demonstrate that a maximal exercise-induced increase in uridine concentration is correlated with the post-exercise increase of UA concentration and SBP. Thus, it appears that Urd may be an indicator of post-exercise hyperuricemia and blood pressure.

\section{Conflict of Interest}

There is no conflict of interest.

\section{Acknowledgements}

This study was supported by a research grant, NN 404 281337, from the Ministry of Science and Higher Education, Poland. We are very grateful to Ms. Marta Kolasinska for correcting the English grammar and style of the final version of the manuscript.

\section{References}

ALPER AB Jr, CHEN W, YAU L, SRINIVASAN SR, BERENSON GS, HAMM LL: Childhood uric acid predicts adult blood pressure: the Bogalusa Heart Study. Hypertension 45: 34-38, 2005.

ASTRAND PO, RODAHL K: Textbook of Work Physiology: Physiological Bases of Exercise. McGraw-Hill Company, New York, 1986.

BLAIR S, CHENG Y, HOLDER J: Is physical activity or physical fitness more important in defining health benefits? Med Sci Sports Exerc 33: 379-385, 2001. 
BURAKOWSKI S, SMOLEŃSKI RT, BELLWON J, KUBASIK A, CIEĆWIERZ D, RYNKIEWICZ A: Exercise stress test and comparison of ST change with cardiac nucleotide catabolite production in patients with coronary artery disease. Cardiol J 14: 573-579, 2007.

CHU NF, WANG DJ, LIOU SH, SHIEH SM: Relationship between hyperuricemia and other cardiovascular disease risk factors among adult males in Taiwan. Eur J Epidemiol 16: 13-17, 2000.

CONNOLLY GP, DULEY JA: Uridine and its nucleotides: biological actions, therapeutic potentials. Trends Pharmacol Sci 20: 218-225, 1999.

DE BRUIN NM, KILIAM AJ, DE WILDE MC, BROERSEN LM: Combined uridine and choline administration improves cognitive deficits in spontaneously hypertensive rats. Neurobiol Learn Mem 80: 63-79, 2003.

DUDZINSKA W, LUBKOWSKA A, DOLEGOWSKA B, SAFRANOW K: Blood uridine concentration may be an indicator of the degradation of pyrimidine nucleotides during physical exercise with increasing intensity. J Physiol Biochem 66: 189-196, 2010.

FIASCHI E, BAGGIO B, FAVARO S, ANTONELlO A, CAMERIN E, TODESCO S, BORSATTI A: Fructoseinduced hyperuricemia in essential hypertension. Metabolism 26: 1219-1223, 1997.

GUIDELINES COMMITTEE: 2003 European Society of Hypertension-European Society of Cardiology guidelines for the management of arterial hypertension. J Hypertens 21: 1011-1053, 2003.

HAMADA T, MIZUTA E, YANAGIHARA K, KAETSU Y, SUGIHARA S, SONOYAMA K, YAMAMOTO Y, KATO M, IGAWA O, SHIGEMASA C, INOKUCHI T, YAMAMOTO T, SHIMADA T, OHTAHARA A, NINOMIYA H, HISATOME I: Plasma levels of uridine correlate with blood pressure and indicators of myogenic purine degradation and insulin resistance in hypertensive patients. Circ J 71: 354-356, 2007.

HARKNESS RA: Hypoxanthine, xanthine and uridine in body fluids, indicators of ATP depletion. J Chromatogr 429: 255-278, 1988.

HELLSTEN Y, RICHTER EA, KIENS B, BANGSBO J: AMP deamination and purine exchange in human skeletal muscle during and after intense exercise. J Physiol 520: 909-920, 1999.

HELLSTEN-WESTING Y, EKBLOM B, SJODIN B: The metabolic relation between hypoxanthine and uric acid in man following maximal short-distance running. Acta Physiol Scand 137: 341-345, 1989.

HELLSTEN-WESTING YA, SOLLEVI A, SJODIN B: Plasma accumulation of hypoxanthine, uric acid and creatine kinase following exhausting runs of differing durations in man. Eur J Appl Physiol 62: 380-384, 1991.

JANKOWSKI V, TÖLLE M, VANHOLDER R, SCHÖNFELDER G, VAN DER GIET M, HENNING L, SCHLÜTER H, PAUL M, ZIDEK W, JANKOWSKI J: Uridine adenosine tetraphosphate: a novel endothelium-derived vasoconstrictive factor. Nat Med 11: 223-227, 2005.

JIN M, YANG F, YANG I, YIN Y, LUO JJ, WANG H, YANG XF: Uric acid, hyperuricemia and vascular disease. Front Biosci 17: 656-669, 2012.

LAUKKANEN JA, KURL S: Blood pressure responses during exercise testing - is up best for prognosis? Ann Med 44: 218-224, 2012.

LEITE ML: Uric acid and fibrinogen: age-modulated relationship with blood pressure components. $J$ Hum Hypertens 25: 476-483, 2011.

LÖFFLER M, FAIRBANKS LD, ZAMEITAT E, MARINAKI AM, SIMMONDS HA: Pyrimidine pathways in health and disease. Trends Mol Med 11: 430-437, 2005.

MACDONALD G, ASSEF R, GUIFFRE A, LO E: Vasoconstrictor effects of uridine and its nucleotides and their inhibition by adenosine. Clin Exp Pharmacol Physiol 11: 381-384, 1984.

MATSUMOTO T, TOSTES RC, WEBB RC: Uridine adenosine tetraphosphate-induced contraction is increased in renal but not pulmonary arteries from DOCA-salt hypertensive rats. Am J Physiol 301: 409-417, 2011.

MESSERLI FH, FROHLICH ED, DRESLINSKI GR: Serum uric acid in essential hypertension: an indicator of renal vascular involvement. Ann Intern Med 93: 817-827, 1980.

NAGAHAMA K, INOUE T, ISEKI K, TOUMA T, KINJO K, OHYA Y, TAKISHITA S: Hyperuricemia as a predictor of hypertension in a screened cohort in Okinawa, Japan. Hypertens Res 27: 835-841, 2004. 
O'BRIEN E, ASMAR R, BEILIN L, IMAI Y, MALLION JM, MANCIA G, MENGDEN T, MYERS M, PADFIELD P, PALATIN P, PARATI G, PICKERING T, REDON J, STAESSEN J, STERGIOU G, VERDECCHIA P; EUROPEAN SOCIETY OF HYPERTENSION WORKING GROUP ON BLOOD PRESSURE MONITORING: European Society of Hypertension recommendations for conventional, ambulatory and home blood pressure measurement. J Hypertens 21: 821-848, 2003.

OHTAHARA A, HISATOME I, YAMAMOTO Y, FURUSE M, SONOYAMA K, FURUSE Y, HAMADA T, KATOH M, WATANABE M, KINUGAWA T, OGINO K, IGAWA O, SHIMOMURA T, MURAKAMI F, YAMAMOTO T, SHIGEMASA C: The release of the substrate for xanthine oxidase in hypertensive patients was suppressed by angiotensin converting enzyme inhibitors and alpha1-blockers. J Hypertens 19: 575-582, 2001.

SAHLIN K, EDBERG K, CIZINSKY S: Changes in plasma hypoxanthine and free radical markers during exercise in man. Acta Physiol Scand 142: 275-281, 1991.

SILEI V, POLITI V, LAURO GM: Uridine induces differentiation in human neuroblastoma cells via protein kinase C epsilon. J Neurosci Res 61: 206-211, 2000.

SJÖDIN B, HELLSTEN WESTING Y: Changes in plasma concentration of hypoxanthine and uric acid in man with short-distance running at various intensities. Int J Sports Med 11: 493-495, 1990.

SMOLENSKI RT, LACHNO DR, LEDINGHAM SJM, YACOUB MH: Determination of sixteen nucleotides, nucleosides and bases using high-performance liquid chromatography and its application to the study of purine metabolism in heart for transplantation. J Chromatogr 527: 414-420, 1990.

STATHIS CG, FEBBRAIO MA, CAREY MF, SNOW RJ: Influence of sprint training on human skeletal muscle purine nucleotide metabolism. J Appl Physiol 76: 1802-1809, 1994.

SUNDSTROM J, SULLIVAN L, D’AGOSTINO RB, LEVY D, KANNEL WB, VASAN RS: Relations of serum uric acid to longitudinal blood pressure tracking and hypertension incidence. Hypertension 45: 28-33, 2005.

SUTTON JR, TOEWS CJ, WARD GR: Purine metabolism during strenuous muscular exercise in man. Metabolism 29: 254-259, 1980.

TYKARSKI A, ŁOPATKA P, POSADZY-MAŁACZYŃSKA A, GŁUSZEK J: Mechanism of hyperuricemia in severe primary hypertension. (in Polish) Arterial Hypertension 8: 411-423, 2004.

WORLD HEALTH ORGANIZATION: Obesity: Preventing and Managing the Global Epidemic. Report of a WHO Consultation on Obesity. WHO, Geneva, 1998.

YAMAMOTO T, MORIWAKI Y, TAKAHASHI S, TSUTSUMI Z, YAMAKITA J, HIGASHINO K: Effect of muscular exercise on the concentration of uridine and purine bases in plasma - adenosine triphosphate consumption-induced pyrimidine degradation. Metabolism 46: 1339-1342, 1997a.

YAMAMOTO T, MORIWAKI Y, TAKAHASHI S, TSUTSUMI Z, YAMAKITA J, HIGASHINO K: Is the plasma uridine level a marker of the overproduction of uric acid? Metabolism 46: 801-804, $1997 \mathrm{~b}$.

YAMAMOTO T, MORIWAKI Y, TAKAHASHI S, YAMAKITA J, TSUTSUMI Z, OHATA H, HIROISHI K, NAKANO T, HIGASHINO K: Effect of ethanol and fructose on plasma uridine and purine bases. Metabolism 46: 544-547, $1997 \mathrm{c}$.

YAMAMOTO T, KOYAMA H, KURAJOH M, SHOJI T, TSUTSUMI Z, MORIWAKI Y: Biochemistry of uridine in plasma. Clin Chim Acta 412: 1712-1724, 2011.

YAMANAKA H, KAWAGOE Y, TANIGUCHI A, KANEKO N, KIMATA S, HOSODA S, KAMATANI N, KASHIWAZAKI S: Accelerated purine nucleotide degradation by anaerobic but not by aerobic ergometer muscle exercise. Metabolism 41: 364-369, 1992. 